\title{
Early Cholecystectomy for Acute Cholecystitis in the Elderly Population: A Systematic Review and Meta-Analysis
}

\author{
Charlotte S. Loozen Bert van Ramshorst Hjalmar C. van Santvoort \\ Djamila Boerma
}

Department of Surgery, St. Antonius Hospital, Nieuwegein, The Netherlands

\section{Key Words}

Acute cholecystitis · Early cholecystectomy · Elderly

\begin{abstract}
Background: In the era of advanced surgical techniques and improved perioperative care, the willingness to perform emergency operations in elderly patients continues to increase. This systematic review aimed at assessing the clinical outcomes of early cholecystectomy in elderly patients with acute cholecystitis. Methods: Medline, Embase, and Cochrane Library databases were systematically searched for studies reporting on early cholecystectomy for acute cholecystitis in patients aged $\geq 70$ years. The conversion rate, perioperative morbidity, and mortality were calculated using a random-effects model. Results: Eight articles fell within the scope of this study. In total, 592 patients were identified. The mean age was 81 years. Early cholecystectomy was performed laparoscopically in 316 patients (53\%) and open in 276 patients (47\%). The procedure was associated with a conversion rate of $23 \%(95 \% \mathrm{Cl}$ 18.6-28.3), a perioperative morbidity of $24 \%(95 \%$ Cl $20.5-$ $27.5)$, and a mortality of $3.5 \%(95 \% \mathrm{Cl} 2.3-5.4)$. Conclusion: Early cholecystectomy seems to be a feasible treatment in elderly patients with acute cholecystitis. To reduce morbidity, patients who may benefit from surgery ought to be selected carefully. Future prospective studies should com-
\end{abstract}

\section{KARGER}

(C) 2017 S. Karger AG, Basel

E-Mail karger@karger.com

www.karger.com/dsu pare early cholecystectomy with alternative treatments to select the treatment that is most appropriate for elderly patients.

c 2017 S. Karger AG, Basel

\section{Introduction}

Acute calculous cholecystitis is a complication of cholelithiasis; a condition that afflicts more than 20 million Americans annually [1]. The prevalence of gallstones increases with age; the prevalence ranges from 20 to $30 \%$ in patients aged $\geq 60$ years $[2,3]$ and increases to $80 \%$ in institutionalized individuals aged $\geq 90$ years [4]. In the United States, the population aged $\geq 65$ years has been estimated to be 43.1 million in 2012 and is projected to be 82.7 million in 2050 [5]. As a result, the incidence of acute calculous cholecystitis will also increase.

In young and otherwise healthy patients, early cholecystectomy is generally accepted as the standard treatment of acute cholecystitis [6-11]. It is preferred over delayed cholecystectomy since the latter is associated with higher complication rates, longer hospital stay, higher costs, and lower patient satisfaction [12]. In elderly patients, the optimal treatment of acute cholecystitis remains controversial. In view of the ageing population, addressing this controversy becomes a matter of increasing urgency. 
Due to comorbidities and reduced physiological reserves, the elderly are thought to be at risk for increased perioperative morbidity and mortality. In daily practice, percutaneous drainage is often preferred over cholecystectomy in the elderly population. However, no randomized controlled trials have been published to substantiate this practice. A systematic review published in 2009 analyzed the safety and efficacy of percutaneous drainage for acute cholecystitis in the elderly and critically ill patients and reported a mortality rate of up to $15 \%$ [13].

In this era of advanced surgical techniques and improved perioperative care, the willingness to offer surgery at initial presentation to elderly patients and those with significant comorbidities continues to increase. This systematic review aims to assess the clinical outcomes of early cholecystectomy in elderly patients with acute cholecystitis.

\section{Material and Methods}

A systematic review was conducted following the guidance of the Centre for Reviews and Dissemination with respect to reviews in healthcare, and was reported in accordance with the PRISMA statement $[14,15]$.

\section{Literature Search}

In July 2016, a literature search was performed by 2 independent reviewers (C.S.L. and D.B.) to identify studies reporting on early laparoscopic cholecystectomy (LC) for acute cholecystitis in the elderly. Medline, Embase, and Cochrane Library databases were searched for articles containing the following keywords and/ or synonyms: "acute cholecystitis" or "acute calculous cholecystitis" in combination with "cholecystectomy" and "aged" or "geriatrics" or "elderly" or "eldest" or "septuagenarian" or "octogenarian" or "nonagenarian" or "centenarian" or "supercentenarian" or "old" or "older." The search had been limited to articles in English and Dutch and published after January 1990 in order to represent current clinical practice.

\section{Study Selection}

Duplicates were removed. Titles and abstracts were independently screened by the reviewers (C.S.L. and D.B.) to assess the relevance of the publications. Subsequently, full-text articles were retrieved and checked. The remaining articles were surveyed by cross referenced search in order to detect studies that might have been overlooked. In case the methods or results were unclear, authors were contacted to seek clarification. Excluded were reviews, case reports, and articles of which no full text was available (Fig. 1). All studies concerning elderly patients (i.e., aged $\geq 70$ years) treated with early cholecystectomy for acute calculous cholecystitis were considered eligible for inclusion. The criteria for the diagnosis of acute cholecystitis had to be defined in the article, and acute cholecystitis had to be proven either by ultrasound or histologically.

\section{Data Collection}

Data were extracted from the full-text articles by both reviewers independently. The methodological index for non-randomized studies (MINORS) score was used to assess the risk of bias. The global ideal score was 16 for non-comparative studies and 24 for comparative studies [16].

\section{Outcomes}

The specific outcomes to be assessed were conversion rate from laparoscopic to open cholecystectomy (OC), perioperative morbidity, perioperative mortality, and length of hospital stay (LOS).

\section{Statistical Analysis}

The perioperative outcomes were valued based on the proportion of events and the $95 \%$ CI. In comparative studies in which data of only one group were relevant, data of only that group were used for the analysis. The estimated pooled event rates were calculated by means of a random-effects model, using meta-analysis software version 3.1. Statistical heterogeneity between the included studies was determined by using forest plots and by performing a $\chi^{2}$ ("chi-square") heterogeneity test and by calculating the $I^{2}$ index. A high $I^{2}$ index represents a high suspicion of heterogeneity. All pooled event rates were shown in forest plots, regardless the level of heterogeneity.

\section{Results}

\section{Study Selection}

Figure 1 shows the article selection in accordance with the PRISMA statement $[14,15]$. A total of 202 references were identified through electronic search. Cross referenced search did not lead to new articles. Seventy-four duplicates were removed and the remaining potentially relevant articles were screened on title and abstract. Eighty-five articles were excluded because of irrelevancy. The remaining 43 manuscripts were assessed for eligibility based on full text. Eight studies met the inclusion criteria and were used in the final analysis. The reasons for excluding articles are shown in Figure 1. Regarding the inclusion of studies, there was total agreement between both the authors (C.S.L. and D.B.).

\section{Characteristics of the Included Studies}

The characteristics of the 8 included studies [17-24] are visualized in Table 1. Six studies [17-19, 21, 22, 24] identified patients retrospectively, 1 study [20] retrospectively identified patients from a prospectively maintained database, and 1 study [23] had a prospective design using standardized case report forms to collect data.

Five of the included studies [17-21] were designed to compare the perioperative outcomes of early cholecystectomy for acute cholecystitis in elderly and younger pa- 
Fig. 1. PRISMA flow diagram of study se-

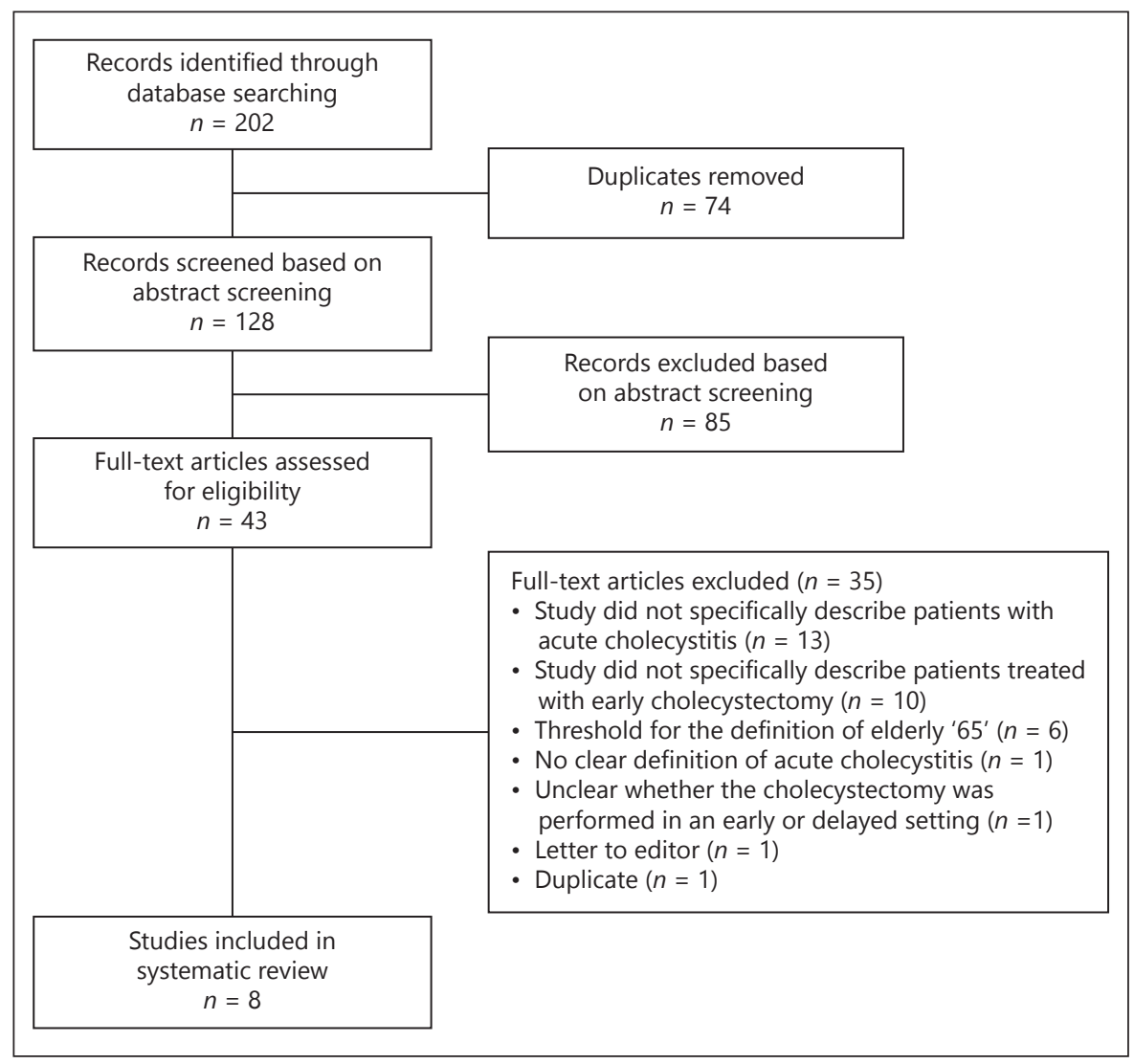
lection process.

Table 1. Demographic information of the included studies

\begin{tabular}{|c|c|c|c|c|c|c|c|}
\hline Study & Year & Country & Design & $\begin{array}{l}\text { Number } \\
\text { of patients }\end{array}$ & $\begin{array}{l}\text { Threshold for } \\
\text { the definition } \\
\text { of elderly, years }\end{array}$ & $\begin{array}{l}\text { Mean age, } \\
\text { years }\end{array}$ & $\begin{array}{l}\text { Patients with } \\
\text { ASA score } \geq 3, \%\end{array}$ \\
\hline Ambe et al. [17] & 2015 & Germany & $\mathrm{R}$ & 74 & 70 & 78 & 73 \\
\hline Fuks et al. [18] & 2015 & France & $\mathrm{R}$ & 78 & 75 & 82 & 62 \\
\hline Fukami et al. [19] & 2014 & Japan & $\mathrm{R}$ & 24 & 80 & NR & 12 \\
\hline Nikfarjam et al. [20] & 2014 & Australia & $\mathrm{RP}$ & 71 & 80 & NR & 51 \\
\hline Fujikawa et al. [21] & 2012 & Japan & $\mathrm{R}$ & 27 & 70 & $77^{\mathrm{a}}$ & 26 \\
\hline Chau et al. [22] & 2002 & Hong Kong & $\mathrm{R}$ & 73 & 75 & 80 & 32 \\
\hline Pessaux et al. [23] & 2001 & France & $\mathrm{P}$ & 139 & 75 & 82 & 36 \\
\hline Makinen and Nordback [24] & 1993 & Finland & $\mathrm{R}$ & 106 & 70 & NR & NR \\
\hline
\end{tabular}

Data are presented as mean unless stated otherwise, ${ }^{\mathrm{a}}$ median.

ASA, American Society of Anesthesiologist; R, retrospective study; P, prospective study; RP, retrospective analysis of prospectively collected data; NR, not reported.

tients. Two studies $[22,23]$ were designed to compare laparoscopic with $\mathrm{OC}$ in the early treatment of elderly patients with acute cholecystitis. The remaining study [24] aimed to determine the feasibility of OC in the elderly population.

Early Cholecystectomy in Elderly

\section{Risk of Bias}

Table 2 shows the methodological quality assessment of the included studies, all of which had a non-randomized design. 


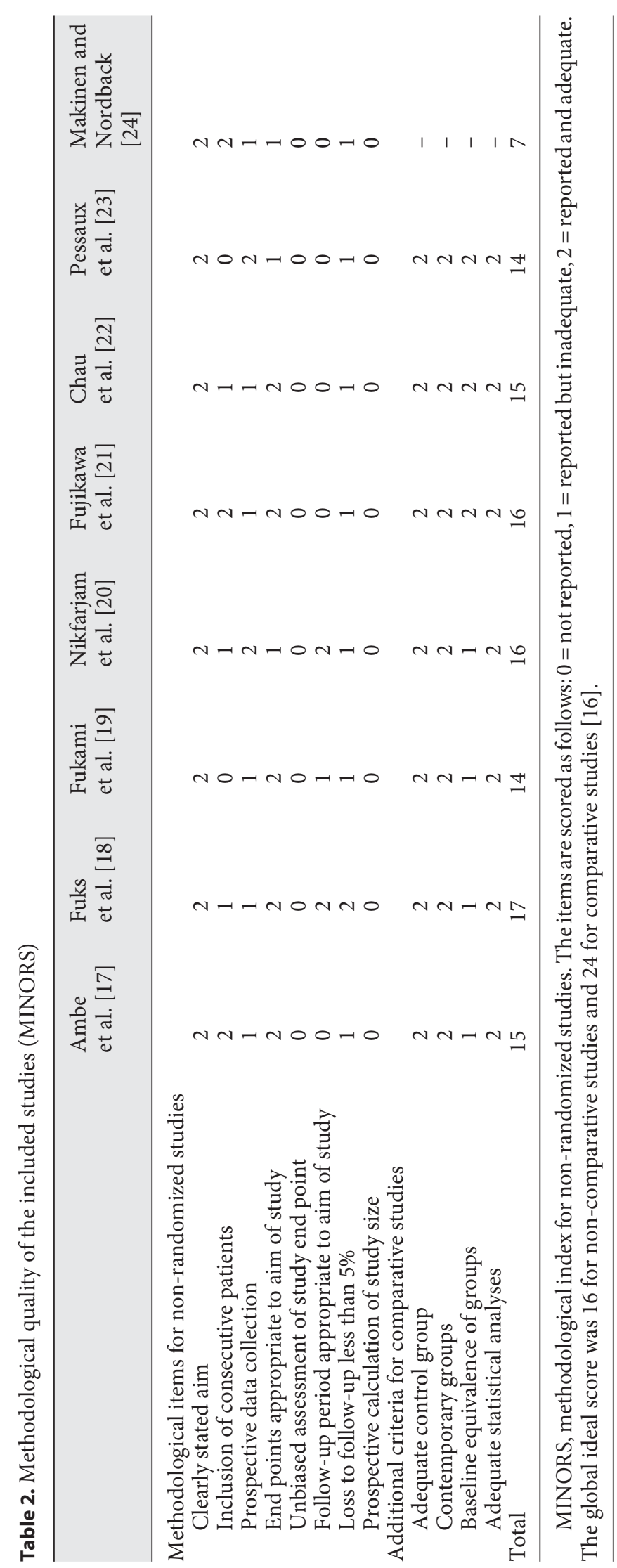

\section{Outcomes}

In total, 592 elderly patients treated with early cholecystectomy for acute cholecystitis were identified (Table 3). The mean age was 81 years. Nearly half of the patients (44\%) had an American Society of Anesthesiologist score of $\geq 3$. Early cholecystectomy was primarily performed laparoscopically in 316 patients (53\%) and open in 276 patients (47\%). The operating time varied from 72 to $134 \mathrm{~min}$.

\section{Conversion Rate}

Seven studies [17-23] reported on the conversion rate from laparoscopic to OC, ranging from 7 to $36 \%$. In total, 69 of the 316 (22\%) laparoscopic procedures were converted. The most commonly reported reasons for conversion were concerns regarding anatomy, the presence of common bile duct stones, and difficulties with the dissection of Calot's triangle due to severe inflammation. The estimated pooled conversion rate was $23 \%$ (95\% CI $18.6-$ 28.3; Fig. 2). Heterogeneity was low between the included studies $\left(I^{2}=47 \%\right)$.

\section{Perioperative Morbidity}

The perioperative complication rate was reported in all included studies, ranging from 4 to $31 \%$ (Table 3 ). Complications either directly or indirectly related to the surgical procedure were seen in 136 (23\%) of the 592 patients. A total of 155 complications were reported, including pulmonary complications $(n=43)$, wound complications $(n=37)$, cardiac complications $(n=13)$, bile leakages $(n=12)$, intra-abdominal abscesses $(n=7)$, fever of unknown origin $(n=6)$, intraperitoneal hemorrhages $(n=5)$, retained stones $(n=4)$, septicemia $(n=4)$, urinary tract infections $(n=4)$, delayed gastric emptying $(n=3)$, acute renal failures $(n=2)$, pancreatitis $(n=2)$, strokes $(n=2)$, thromboembolic complications $(n=1)$, psychosis $(n=1)$, iatrogenic complication $(n=1)$, and non-specified complications $(n=8)$. The estimated pooled morbidity was $23.8 \%$ (95\% CI 20.5-27.5; Fig. 3). The included studies showed a low degree of heterogeneity $\left(I^{2}=27 \%\right)$.

\section{Mortality}

All included studies [17-24] reported on the perioperative mortality, ranging from 0 to $5 \%$ (Table 3 ). Nineteen of the 592 elderly patients died following early cholecystectomy $(3 \%)$. The causes of death were pulmonary complications $(n=5)$, cardiac complications $(n=4)$, multisystem organ failure $(n=1)$, and disseminated intravascular coagulopathy due to chronic liver cirrhosis $(n=1)$. 
Fig. 2. Forest plot of the conversion rate of early laparoscopic cholecystectomy for acute cholecystitis in elderly patients.

\begin{tabular}{|c|c|c|c|c|c|c|}
\hline \multicolumn{7}{|c|}{ Complication rate } \\
\hline & Total & $\begin{array}{l}\text { Event } \\
\text { rate }\end{array}$ & $\begin{array}{c}\text { Lower } \\
\text { limit }\end{array}$ & $\begin{array}{l}\text { Upper } \\
\text { limit }\end{array}$ & & \\
\hline Ambe, 2015 & $18 / 74$ & 0.243 & 0.159 & 0.353 & & \\
\hline Fuks, 2015 & $17 / 78$ & 0.218 & 0.140 & 0.323 & - & \\
\hline Fukami, 2014 & $4 / 24$ & 0.167 & 0.064 & 0.369 & & \\
\hline Nikfarjam, 2014 & $22 / 71$ & 0.310 & 0.214 & 0.426 & & \\
\hline Fujikawa, 2012 & $1 / 27$ & 0.037 & 0.005 & 0.221 & & \\
\hline Chau, 2002 & $21 / 73$ & 0.288 & 0.196 & 0.401 & & \\
\hline Pessaux, 2001 & $27 / 139$ & 0.194 & 0.137 & 0.268 & & \\
\hline \multirow[t]{2}{*}{ Makinen, 1993} & $26 / 106$ & 0.245 & 0.173 & 0.336 & & \\
\hline & $136 / 592$ & 0.238 & 0.205 & 0.275 & & \\
\hline \multicolumn{7}{|c|}{ Overall $\left(I^{2}=26.7 \%, p=0.216\right)$} \\
\hline & & & & & 0.25 & 0.50 \\
\hline
\end{tabular}

\begin{tabular}{|c|c|c|c|c|c|c|}
\hline \multicolumn{7}{|l|}{ Conversion rate } \\
\hline & Total & $\begin{array}{c}\text { Event } \\
\text { rate }\end{array}$ & $\begin{array}{c}\text { Lower } \\
\text { limit }\end{array}$ & $\begin{array}{l}\text { Upper } \\
\text { limit }\end{array}$ & & \\
\hline Ambe, 2015 & $15 / 65$ & 0.231 & 0.144 & 0.348 & & \\
\hline Fuks, 2015 & $10 / 64$ & 0.156 & 0.086 & 0.267 & & \\
\hline Fukami, 2014 & $1 / 11$ & 0.091 & 0.013 & 0.439 & 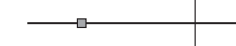 & \\
\hline Nikfarjam, 2014 & $14 / 68$ & 0.206 & 0.126 & 0.318 & 7 & \\
\hline Fujikawa, 2012 & $2 / 27$ & 0.074 & 0.019 & 0.252 & $\square-$ & \\
\hline Chau, 2002 & $11 / 31$ & 0.355 & 0.209 & 0.534 & & $\rightarrow$ \\
\hline \multirow[t]{2}{*}{ Pessaux, 2001} & $16 / 50$ & 0.320 & 0.206 & 0.460 & & \\
\hline & $69 / 316$ & 0.231 & 0.186 & 0.283 & & \\
\hline \multicolumn{7}{|c|}{ Overall $\left(I^{2}=47.1 \%, p=0.078\right)$} \\
\hline & & & & & 0.25 & 0.50 \\
\hline
\end{tabular}

Fig. 3. Forest plot of the complication rate of early cholecystectomy for acute cholecystitis in elderly patients.
Table 3. Perioperative outcome of early cholecystectomy for acute cholecystitis in elderly patients

\begin{tabular}{|c|c|c|c|c|c|c|}
\hline Study & $\begin{array}{l}\text { Number } \\
\text { of patients }\end{array}$ & $\begin{array}{l}\text { Patients treated } \\
\text { with LC/OC, } n\end{array}$ & $\begin{array}{l}\text { Conversion, } \\
n(\%)\end{array}$ & $\begin{array}{l}\text { Overall morbidity, } \\
n(\%)\end{array}$ & $\begin{array}{l}\text { Mortality, } \\
n(\%)\end{array}$ & $\begin{array}{l}\text { Postoperative } \\
\text { LOS, days }\end{array}$ \\
\hline Ambe et al. [17] & 74 & $65 / 9$ & $15(23)$ & $18(24)$ & $2(3)$ & 13 \\
\hline Fuks et al. [18] & 78 & $64 / 14$ & $10(16)$ & $17(22)$ & $1(1)$ & $7^{\mathrm{a}}$ \\
\hline Fukami et al. [19] & 24 & $11 / 13$ & $1(9)$ & $4(17)$ & $1(4)$ & 9 \\
\hline Nikfarjam et al. [20] & 71 & $68 / 3$ & $14(21)$ & $22(31)$ & $3(4)$ & $7^{\mathrm{a}}$ \\
\hline Fujikawa et al. [21] & 27 & $27 / 0$ & $2(7)$ & $1(4)$ & 0 & 7 \\
\hline Chau et al. [22] & 73 & $31 / 42$ & $11(36)$ & $21(29)$ & $3(4)$ & 9 \\
\hline Pessaux et al. [23] & 139 & $50 / 89$ & $16(32)$ & $27(19)$ & $4(3)$ & 11 \\
\hline Makinen and Nordback [24] & 106 & $0 / 106$ & NA & $26(25)$ & $5(5)$ & NR \\
\hline Total & 592 & $316 / 276$ & $69(22)$ & $136(23)$ & $19(3)$ & \\
\hline
\end{tabular}

Data are presented as mean unless stated otherwise, ${ }^{\mathrm{a}}$ median.

LC, laparoscopic cholecystectomy; OC, open cholecystectomy; NA, not applicable; NR, not reported; LOS, length of hospital stay. 
Fig. 4. Forest plot of the mortality of early cholecystectomy for acute cholecystitis in elderly patients.

\begin{tabular}{|c|c|c|c|c|c|c|c|}
\hline \multicolumn{8}{|l|}{ Mortality rate } \\
\hline Studies & Total & $\begin{array}{c}\text { Event } \\
\text { rate }\end{array}$ & $\begin{array}{l}\text { Lower } \\
\text { limit }\end{array}$ & $\begin{array}{c}\text { Upper } \\
\text { limit }\end{array}$ & & & \\
\hline Ambe, 2015 & $2 / 74$ & 0.027 & 0.007 & 0.102 & $\square$ & & \\
\hline Fuks, 2015 & $1 / 78$ & 0.013 & 0.002 & 0.085 & $\square-$ & & \\
\hline Fukami, 2014 & $1 / 24$ & 0.042 & 0.006 & 0.244 & $\hookrightarrow-$ & & \\
\hline Nikfarjam, 2014 & $3 / 71$ & 0.042 & 0.014 & 0.123 & $-\square$ & & \\
\hline Fujikawa, 2012 & $0 / 27$ & 0.018 & 0.001 & 0.230 & $\rightarrow$ & & \\
\hline Chau, 2002 & $3 / 73$ & 0.041 & 0.013 & 0.120 & $-\square$ & & \\
\hline Pessaux, 2001 & $4 / 139$ & 0.029 & 0.011 & 0.074 & $\square$ & & \\
\hline \multirow[t]{2}{*}{ Makinen, 1993} & $5 / 106$ & 0.047 & 0.020 & 0.108 & & & \\
\hline & $19 / 592$ & 0.035 & 0.023 & 0.054 & $\Delta$ & & \\
\hline \multicolumn{8}{|c|}{ Overall $\left(I^{2}=0 \%, p=0.944\right)$} \\
\hline & & & & & 0 & 0.25 & 0.50 \\
\hline
\end{tabular}

In 8 patients, the cause of death was not specified. Three studies $[18,19,23]$ reported the characteristics of the patients who died, showing that they all suffered from severe pre-existent comorbidities or had a poor clinical preoperative condition. The estimated pooled mortality was $3.5 \%$ (95\% CI 2.3-5.4). There was no heterogeneity between the included studies ( $I^{2}=0 \%$; Fig. 4$)$.

\section{Postoperative LOS}

Seven studies described the postoperative LOS [1723], 2 studies $[18,20]$ reported a median duration of 7 days, and 5 studies $[17,19,21-23]$ reported a mean duration of 11 days ranging from 7 up to 13 days.

\section{Discussion}

This systematic review demonstrated that early cholecystectomy for acute cholecystitis in patients aged $\geq 70$ years is associated with a perioperative morbidity of $24 \%$ and a mortality of $3.5 \%$.

These rates are higher than reported for non-elderly patients undergoing emergency cholecystectomy for acute cholecystitis, which has been extensively investigated in previous studies, being approximately 15 and $<1 \%$, respectively [25]. Yet, 4 of the 5 included studies comparing perioperative outcomes of early cholecystectomy in elderly and younger patients showed no significant difference in terms of perioperative morbidity or mortality $[17-19,21]$. Only one study proved older age to be independently associated with increased morbidity [20].
Elderly patients may have more comorbidity and often present with clinical signs of a more severe cholecystitis in terms of systemic sequelae as compared to younger patients [17-21]. Many of the complications encountered in this meta-analysis, such as pulmonary and cardiac complications as well as death, could be attributed to reduced physiological reserves and pre-existent comorbidities rather than to the surgical procedure itself. Minor complications such as wound infections were also frequently encountered but had minor impact on the final outcome. It is noteworthy that only 2 studies $[17,19]$ reported on the severity of each complication, both by using the Clavien-Dindo classification [26]. The remaining studies neither mentioned the severity of the complications nor whether the patients had fully recovered from the complications.

Studies focusing on non-elderly patients undergoing early cholecystectomy for acute cholecystitis demonstrated a conversion rate from laparoscopic to OC of 13\% [25]. The present study showed a conversion rate of $23 \%$. This high rate may have resulted in increased perioperative morbidity, as OC compared to LC for acute cholecystitis is associated with increased risk of complications ( $28 \mathrm{vs.}$ $18 \%, p=0.03$ ) [27]. A recent meta-analysis of observational studies showed that advanced age is associated with increased risk of conversion, although no obvious explanation is given [28]. Dense adhesions due to previous episodes of complicated gallstone disease or previous abdominal surgery, or perioperative cardiopulmonary complications may be the reason $[19,21]$. In the present review, only 2 studies $[22,23]$ reported on the morbidity in the converted patients, showing no significant differ-

Loozen/van Ramshorst/van Santvoort/ Boerma 
ence in morbidity with patients successfully treated with LC.

An alternative for urgent cholecystectomy in elderly patients is percutaneous drainage in addition to appropriate systemic support and antibiotic treatment. This minimally invasive procedure avoids the risk associated with general anesthesia and can be performed either as a bridge to surgery or as a definitive treatment $[29,30]$. In the literature, it is described as a rather uncomplicated procedure with low complication rates and high success rates [31-33]. The reported 30-day mortality, however, is higher than that of acute cholecystectomy, but this may likely be a result of selection bias since the available literature is mainly retrospective [13]. Eventually, almost half of the patients treated with percutaneous drainage eventually underwent a cholecystectomy, which indicates that drainage alone is not the definitive treatment for a large proportion of patients [13]. Early cholecystectomy in this respect provides a one-shot definitive treatment. Whether emergency cholecystectomy is a better choice than percutaneous drainage remains unclear. A clinical trial comparing both treatment strategies is currently being conducted (CHOCOLATE trial, NTR2666) [34]. The results of this trial will become available in 2017.

Conservative management (i.e., non-invasive management) is another option for the treatment of elderly patients with acute cholecystitis. Since the source of infection is not controlled using this approach though, many patients might still develop biliary sepsis. A prospective study of 53 elderly patients with acute cholecystitis treated conservatively showed that 16 patients $(30 \%)$ suffered from biliary sepsis requiring emergency surgery, one of whom died [35]. A prospective study of 42 elderly patients with acute cholecystitis and an APACHE-II score $\geq 12$ showed that 7 patients (17\%) suffered from ongoing sepsis, all of whom died [36]. In addition, since the gallbladder is left in situ, there is a chance of recurrent gallstone-related disease in at least 22\% [37].

Although increased morbidity and mortality are inextricably linked to any treatment strategy for acute cholecystitis in elderly patients, the outcome of early cholecystectomy in elderly patients may be improved by several measures.

First, applying strict criteria to select patients who might benefit from early cholecystectomy may contribute to a better perioperative outcome. Fuks et al. [18] assessed the perioperative outcome of early cholecystectomy in elderly patients and included only patients with grades I and II acute cholecystitis based on the severity assessment criteria of the Tokyo Guidelines [38]. Patients with either

Early Cholecystectomy in Elderly grade III acute cholecystitis (i.e., cholecystitis accompanied by organ dysfunction) or complaints lasting longer than 5 days were excluded. Early cholecystectomy in the grade I and II group turned out to be associated with a perioperative outcomes similar to that observed in their younger counterparts, and is assumed to be appropriate and safe. To reduce the risk of perioperative morbidity and mortality, a severity assessment of pre-existing comorbid conditions should be performed. This review showed that patients who died had been suffering from severe pre-existent comorbidities or a poor clinical preoperative condition $[18,19,23]$. Careful selection of elderly patients who may benefit from surgery, that is, those patients in good physical health having very few comorbidities, may contribute to a better perioperative outcome.

Second, elderly surgical patients require a different level of perioperative care than younger patients. To provide optimal care, a thorough preoperative assessment of the individual's health status is essential to identify factors associated with increased risks of specific complications and to recommend a management plan that could minimize these risks [39]. Specialists from multiple disciplines should be involved in the preoperative optimization of comorbidities and the correction of system deficits.

Third, early cholecystectomy in elderly patients with acute cholecystitis should be performed with the utmost care and prudence. An LC rather than an OC is preferred [27]. Previous studies have shown that LC is more successful if carried out by a laparoscopy-oriented surgeon $[40,41]$. In the present study, the conversion rate appeared to be $18 \%$ if only studies reporting on early cholecystectomy performed by experienced laparoscopic surgeons or performed in a centre specialized in laparoscopic surgery were considered $[17,18,20,21]$.

Lastly, elderly patients require specialized postoperative care since they are prone to developing postoperative complications including pulmonary complications, under nutrition, urinary tract infections, ulcers, delirium, and functional decline [39]. Education of healthcare providers in core geriatric principles, risk factors, the incorporation of evidence-based interventions, and interdisciplinary communication may contribute to improvement of postoperative outcome.

Conclusions based on this systematic review should be drawn with caution. First, all but one study had a retrospective design, carrying the risk of selection bias. The choice of treatment was mostly made at the surgeon's discretion and there was a lack of clear criteria for the assignment of patients to early cholecystectomy. The included

Dig Surg 2017;34:371-379 377 
studies were methodologically of an estimated poor to moderate quality as demonstrated by the MINORS scores in Table 2. Second, the definition of early cholecystectomy was not unequivocal. Four studies [17, 19, 21, 23] used this term to indicate cholecystectomy performed within 3 days of onset of symptoms, 1 study [18] used this term to indicate surgery within 5 days, whereas 3 studies [20, $22,24]$ used the term "urgent cholecystectomy" without specifying the duration of complaints prior to surgery. Furthermore, data possibly relevant in the treatment of elderly such as rate of perioperative delirium, rate of functional decline, and rate of exacerbation of underlying comorbid conditions were not available.

This is the first systematic review examining the clinical outcomes of early cholecystectomy for acute cholecystitis in elderly patients. Based on the best available evidence, early surgical management seems to be a feasible treatment in this patient group. To reduce the risk of perioperative complications, elderly patients who may benefit from surgery should be carefully selected, the procedure should be performed by an experienced laparoscopic surgeon and appropriate perioperative care should be available. Whether early cholecystectomy or percutaneous drainage is better suited in elderly patients with acute cholecystitis will be demonstrated by an ongoing randomized trial [34].

\section{Funding}

None.

\section{Disclosure Statement}

The authors have no conflicts of interest to declare.

\section{References}

1 Everhart JE, Khare M, Hill M, Maurer KR: Prevalence and ethnic differences in gallbladder disease in the United States. Gastroenterology 1999;117:632-639.

2 Lirussi F, Nassuato G, Passera D, Toso S, Zalunardo B, Monica F, et al: Gallstone disease in an elderly population: the Silea study. Eur J Gastroenterol Hepatol 1999;11:485-491.

3 Festi D, Dormi A, Capodicasa S, Staniscia T, Attili AF, Loria P, et al: Incidence of gallstone disease in Italy: results from a multicenter, population-based Italian study (the MICOL project). World J Gastroenterol 2008; 14: 5282-5289.

4 Ratner J, Lisbona A, Rosenbloom M, Palayew M, Szabolcsi S, Tupaz T: The prevalence of gallstone disease in very old institutionalized persons. JAMA 1991;265:902-903.

5 Ortman JM, Velkoff VA, Hogan H: An Aging Nation: The Older Population in the United States. Washington, US Census Bureau, 2014, P25-1140.

6 Papi C, Catarci M, D’ambrosio L, Gili L, Koch M, Grassi GB, et al: Timing of cholecystectomy for acute calculous cholecystitis: a metaanalysis. Am J Gastroenterol 2004;99:147155.

7 Gurusamy KS, Davidson C, Gluud C, Davidson BR: Early versus delayed laparoscopic cholecystectomy for people with acute cholecystitis. Cochrane Database Syst Rev 2013; 6:CD005440.

8 Gurusamy K, Samraj K, Gluud C, Wilson E, Davidson BR: Meta-analysis of randomized controlled trials on the safety and effectiveness of early versus delayed laparoscopic cholecystectomy for acute cholecystitis. Br J Surg 2010;97:141-150.
9 Gutt CN, Encke J, Koninger J, Harnoss JC, Weigand K, Kipfmuller K, et al: Acute cholecystitis: early versus delayed cholecystectomy, a multicenter randomized trial (ACDC study, NCT00447304). Ann Surg 2013;258:385-393.

10 Kolla SB, Aggarwal S, Kumar A, Kumar R, Chumber S, Parshad R, et al: Early versus delayed laparoscopic cholecystectomy for acute cholecystitis: a prospective randomized trial. Surg Endosc 2004; 18:1323-1327.

11 Banz V, Gsponer T, Candinas D, Guller U: Population-based analysis of 4113 patients with acute cholecystitis: defining the optimal time-point for laparoscopic cholecystectomy. Ann Surg 2011;254:964-970.

12 Song GM, Bian W, Zeng XT, Zhou JG, Luo YQ, Tian X: Laparoscopic cholecystectomy for acute cholecystitis: early or delayed?: evidence from a systematic review of discordant meta-analyses. Medicine (Baltimore) 2016; 95:e3835.

13 Winbladh A, Gullstrand P, Svanvik J, Sandström P: Systematic review of cholecystostomy as a treatment option in acute cholecystitis. HPB (Oxford) 2009;11:183-193.

14 Liberati A, Altman DG, Tetzlaff J, Mulrow C, Gøtzsche PC, Ioannidis JP, et al: The PRISMA statement for reporting systematic reviews and meta-analyses of studies that evaluate health care interventions: explanation and elaboration. Ann Intern Med 2009;151:W65W94.

15 Moher D, Liberati A, Tetzlaff J, Altman DG: Preferred reporting items for systematic reviews and meta-analyses: the PRISMA statement. Ann Intern Med 2009;151:264-269.

16 Slim K, Nini E, Forestier D, Kwiatkowski F, Panis Y, Chipponi J: Methodological index for non-randomized studies (MINORS): development and validation of a new instrument. ANZ J Surg 2003;73:712-716.

17 Ambe PC, Weber SA, Christ H, Wassenberg D: Primary cholecystectomy is feasible in elderly patients with acute cholecystitis. Aging Clin Exp Res 2015;27:921-926.

18 Fuks D, Duhaut P, Mauvais F, Pocard M, Haccart V, Paquet JC, et al: A retrospective comparison of older and younger adults undergoing early laparoscopic cholecystectomy for mild to moderate calculous cholecystitis. J Am Geriatr Soc 2015;63:1010-1016.

19 Fukami Y, Kurumiya Y, Mizuno K, Sekoguchi E, Kobayashi S: Cholecystectomy in octogenarians: be careful. Updates Surg 2014;66: 265-268.

20 Nikfarjam M, Yeo D, Perini M, Fink MA, Muralidharan V, Starkey G, et al: Outcomes of cholecystectomy for treatment of acute cholecystitis in octogenarians. ANZ J Surg 2014;84:943-948.

21 Fujikawa T, Tada S, Abe T, Yoshimoto Y, Maekawa $\mathrm{H}$, Shimoike N, et al: Is early laparoscopic cholecystectomy feasible for acute cholecystitis in the elderly? J Gastroenterol Hepatol 2012;1:247-251.

22 Chau CH, Tang CN, Siu WT, Ha JP, Li MK: Laparoscopic cholecystectomy versus open cholecystectomy in elderly patients with acute cholecystitis: retrospective study. Hong Kong Med J 2002;8:394-399.

23 Pessaux P, Regenet N, Tuech JJ, Rouge C, Bergamaschi R, Arnaud JP: Laparoscopic versus open cholecystectomy: a prospective comparative study in the elderly with acute cholecystitis. Surg Laparosc Endosc Percutan Tech 2001;11:252-255. 
24 Makinen AM, Nordback I: Conventional cholecystectomy in elderly patients. Ann Chir Gynaecol 1993;82:241-244.

25 Cao AM, Eslick GD, Cox MR: Early cholecystectomy is superior to delayed cholecystectomy for acute cholecystitis: a meta-analysis. J Gastrointest Surg 2015;19:848-857.

26 Dindo D, Demartines N, Clavien PA: Classification of surgical complications: a new proposal with evaluation in a cohort of $6336 \mathrm{pa}-$ tients and results of a survey. Ann Surg 2004; 240:205-213.

27 Coccolini F, Catena F, Pisano M, Gheza F, Fagiuoli S, Di Saverio S, et al: Open versus laparoscopic cholecystectomy in acute cholecystitis. Systematic review and meta-analysis. Int J Surg 2015;18:196-204.

28 Philip Rothman J, Burcharth J, Pommergaard HC, Viereck S, Rosenberg J: Preoperative risk factors for conversion of laparoscopic cholecystectomy to open surgery - a systematic review and meta-analysis of observational studies. Dig Surg 2016;33:414-423.

29 Simorov A, Ranade A, Parcells J, Shaligram A, Shostrom V, Boilesen E, et al: Emergent cholecystostomy is superior to open cholecystectomy in extremely ill patients with acalculous cholecystitis: a large multicenter outcome study. Am J Surg 2013;206:935-940; discussion 940-941.

30 Kapan M, Onder A, Tekbas G, Gul M, Aliosmanoglu I, Arikanoglu Z, et al: Percutane- ous cholecystostomy in high-risk elderly patients with acute cholecystitis: a lifesaving option. Am J Hosp Palliat Care 2013;30: 167-171.

31 Melloul E, Denys A, Demartines N, Calmes JM, Schäfer M: Percutaneous drainage versus emergency cholecystectomy for the treatment of acute cholecystitis in critically ill patients: does it matter? World J Surg 2011;35:826833.

32 McKay A, Abulfaraj M, Lipschitz J: Short- and long-term outcomes following percutaneous cholecystostomy for acute cholecystitis in high-risk patients. Surg Endosc 2012;26: 1343-1351.

33 Horn T, Christensen SD, Kirkegård J, Larsen LP, Knudsen AR, Mortensen FV: Percutaneous cholecystostomy is an effective treatment option for acute calculous cholecystitis: a 10-year experience. HPB (Oxford) 2015;17: 326-331.

34 Kortram K, van Ramshorst B, Bollen TL, Besselink MG, Gouma DJ, Karsten T, et al: Acute cholecystitis in high risk surgical patients: percutaneous cholecystostomy versus laparoscopic cholecystectomy (CHOCOLATE trial): study protocol for a randomized controlled trial. Trials 2012;13:7.

35 Vracko J, Markovic S, Wiechel KL: Conservative treatment versus endoscopic sphincterotomy in the initial management of acute cholecystitis in elderly patients at high surgical risk. Endoscopy 2006;38:773778.

36 Hatzidakis AA, Prassopoulos P, Petinarakis I, Sanidas E, Chrysos E, Chalkiadakis G, et al: Acute cholecystitis in high-risk patients: percutaneous cholecystostomy vs conservative treatment. Eur Radiol 2002;12:17781784.

37 Loozen CS, Oor JE, van Ramshorst B, van Santvoort HC, Boerma D: Conservative treatment of acute cholecystitis: a systematic review and pooled analysis. Surg Endosc 2016, Epub ahead of print.

38 Yokoe M, Takada T, Strasberg SM, Solomkin JS, Mayumi T, Gomi H, et al: TG13 diagnostic criteria and severity grading of acute cholecystitis (with videos). J Hepatobiliary Pancreat Sci 2013;20:35-46.

39 Optimal Perioperative Management of the Geriatric Patient [Internet]. https://www.facs. org/ /media/files/quality\%20programs/ -geriatric/acs $\% 20$ nsqip $\% 20$ geriatric $\% 20$ 2016\%20guidelines.ashx.

40 Boddy AP, Bennett JM, Ranka S, Rhodes M: Who should perform laparoscopic cholecystectomy? A 10-year audit. Surg Endosc 2007; 21:1492-1497.

41 Kortram K, Reinders JS, van Ramshorst B, Wiezer MJ, Go PM, Boerma D: Laparoscopic cholecystectomy for acute cholecystitis should be performed by a laparoscopic surgeon. Surg Endosc 2010;24:2206-2209. 